\title{
Challenges and requirements for developing data architecture supporting integration of sustainable supply chains by Djoko Sayogo
}

Submission date: 21-Mar-2019 01:32AM (UTC-0700)

Submission ID: 1097127800

File name: itecture_supporting_integration_of_sustainable_supply_chains.pdf (443.47K) Word count: 10402 


\title{
Challenges and requirements for developing data architecture supporting integration of sustainable supply chains
}

\author{
Djoko Sigit Sayogo $\cdot$ Jing Zhang $\cdot$ Luis Luna-Reyes \\ Holly Jarman · Giri Tayi · Deborah Lines Andersen • \\ Theresa A. Pardo · David F. Andersen
}

Published online: 19 December 2014

(c) Springer Science+Business Media New York 2014

\begin{abstract}
Information asymmetry between consumers and supply chain actors represents a major barrier to the expansion of sustainable consumption. Developing an interoperable data architecture that enables the integration of data regarding sustainability practices from disparate sources in sustainable supply chains is important for improving market transparency. This paper identifies main issues and requirements as perceived by the key stakeholders in the coffee supply chain for such development. The analysis reveals that building an interoperable data
\end{abstract}

D. S. Sayogo (ه)

The University of Muhammadiyah at Malang, Malang, Indonesia e-mail: dsayogo@ctg.albany.edu; dsayogo@umm.ac.id

D. S. Sayogo - T. A. Pardo

Center for Technology in Government, University at Albany,

Albany, NY, US 4

e-mail: tpardo@ctg.albany.edu

\section{J. Zhang}

Clark University, Worcester, MA, USA

e-mail: Jizhang@clarku.edu

L. Luna-Reyes

Universidad de las Americas Puebla, Cholula, Mexico

e-mail: luisf.luna@udlap.mx

H. Jarman

University of Michigan, Ann Arbor, MI, USA

e-mail: hjarman@umich.edu

G. Tayi · D. L. Andersen - D. F. Andersen

University at Albany, Albany, NY, USA

e-mail: gtayi@albany.edu

D. L. Andersen

e-mail: dla@albany.edu

D. F. Andersen

e-mail: david.andersen@albany.edu architecture necessitates awareness of several major challenges, including the difficulties of collecting accurate and creditable data, limited technological capabilities, complex data ownership and disclosure policy, issues of confidentiality, privacy and economic value of information, and cost of disclosing information. To deal with these challenges, we recommend that the development need to ensure data quality, integrity and security, design information policy balancing commercial interests and openness, and design appropriate governance mechanism to complement the technological design in order to ensure the fair and proper use of the system.

Keywords Sustainable consumption - Sustainable supply chains - Information integration - Interoperable data architecture $\cdot$ Industrial ecology $\cdot$ I-Choose

\section{Background}

As a result of Agenda 21 from the 1992 Rio Earth Summit, governments around the world committed themselves to promoting more sustainable consumption patterns. The World Commission on Environment and Development (WCED) defines sustainability as "using resources to meet the need of the present without compromising the ability of future generations" [1, p. 1076]. The concept of sustainability encompasses a wide variety of issues such as sustainable production, sustainable consumption and sustainable supply chains. Although each issue deals with a different aspect of sustainability, they all emphasize the importance of adjusting consumption and supply chain management patterns to support sustainable economics.

Advocates of sustainable consumption focus on two approaches: creating eco-efficiencies and "greening" the 
production process, and changing consumption levels and patterns [2-4]. Of these two approaches, changing consumer consumption patterns is regarded as having potentially much higher impact [2]. The assumption is that increased demand for sustainable products will create market incentives for companies to transform their production and supply chain practices. However, increasing demand for sustainable products is highly susceptible to information asymmetry that currently exists in the market [4]. The concept of information asymmetry describes the problem of one actor not having enough information to verify agent behavior [5, 6] or to accurately evaluate information quality and breadth (coverage) [7, 8]. Because information asymmetry limits the ability of consumers to understand the environmental and social implications of their consumption decisions, eliminating or reducing information asymmetry in today's market is necessary to support sustainable consumption.

Efforts to reduce information asymmetry related to environmental and social impacts have led to the proliferation of third party certifications and labels, such as organic or Fairtrade [9]. These labels are supposed to help consumers differentiate between organizations or products in regards to their environmental and social impacts. But with the proliferation of certifications and their diverse standards (there are currently 460 eco labels worldwide in 25 industry sectors) (ecolabelindex, n.d.), the meaning and credibility of any given certification is difficult to assess. Currently, certificates and labels attached to a product do not convey any information about the actual certification criteria or the processes employed to verify these criteria. In other words, consumers are not given enough information to assess the trustworthiness of a label or the robustness of its certification criteria. In fact, Fairtrade and organic labels are embedded in a complex ecosystem of certificates, involving a variety of certification practices and criteria, as well as different policies regulating data ownership. The challenge of providing such information to consumers lies mainly in making vast amounts of disparate data across certifications accessible and useful in a way that would be trusted by consumers. The missing key technical mechanism is a combination of data standards and procedures that would allow data to be shared among diverse stakeholders.

For the past 4 years, our team has worked on a project aimed at creating a set of data standards in the form of a formal ontology of the certification and inspection processes in the certified sustainable coffee supply chain, which we named I-Choose [10]. I-Choose is a proof of concept prototype that envisioned a framework that would enable all supply chain actors and certifiers to share certification information by allowing them to post their data in a standard way. This would allow the development of applications that could help consumers adopt more sustainable consumption patterns on the basis of trusted information. Such applications would provide structured access to full information packages that rest behind each certificate. Moreover, consumer advocates would be able to verify the integrity of the information by comparing standardized information from different data provider ${ }_{5}$ either supply chain firms or certifiers. The envisioned application and usage of I-Choose would help consumers better understand the social and environmenta 5 consequences of their purchase.

An initial focus group involving several stakeholders in the sustainable coffee supply chain suggested that extracting and combining trusted data from different sources was a key issue for I-Choose. This paper explores this challenge in more detail focusing on answering the following questions: (a) what are the main challenges for data owners/producers to disclosing their data to support a data architecture such as I-Choose; and (b) how do these challenges affect the requirements for developing interoperable data architecture such as I-Choose. In this paper we present the main challenges and requirements to be considered in sourcing data to support interoperable data architecture from the viewpoint of key stakeholders in the sustainable coffee supply chain as well as potential develop 5 of such architecture.

This paper is organized into six sections including this introduction. The next section discusses relevant literature on sustainable consumption and the role of information. Section 3 outlines the methodological approach for this study. Section 4 describes the main actors and information flows in certified sustainable coffee supply chain, and then discusses the challenges facing the main data producers in the supply chain to support data architecture such as I-Choose. In Sect. 5 we propose four key requirements that need to be considered in building data architecture such as I-Choose and summarize the potential implications for research and practices. Finally, Sect. 6 provides the conclusion.

\section{Literature review}

In this section, we review literature on sustainable consumption, highlighting the role of information. We also review literature on sustainable supply chains in respect to information integration across different actors in the supply chain and its role in decreasing information asymmetry and supporting value-based decision making by consumers [4].

\subsection{Sustainable consumption and the value} of information in consumer markets

Information systems researchers have been trying to look for ways in which information technologies can contribute to the creation of market transparency and help reduce 
information asymmetry $[11,12]$. However, there is still a need to understand how information systems can be used effectively in a market for sustainable products, such as organic or Fairtrade coffee.

Neoclassical microeconomic theory holds that commodity markets, such as the market for coffee, are instances of perfect competition and as such assume the existence of perfect information (rational choice theory). Under perfect information conditions, a consumer could scrutinize the supply chain and make a purchasing decision that best matches her personal values [13],or a wholesaler could monitor its suppliers' compliance with industry codes of conduct or public standards [14].

In reality, non-price information in commodity markets is difficult to obtain. Information asymmetry is present when unequal distribution of information among stakeholders can impede efficient market outcomes. The degree of information asymmetry typically depends on product quality attributes, namely search, experience, credence and Potemkin [9, 15, 16]. A search attribute (price) can be known before the purchase, and consumers have the ability to search for it. Experience attributes (flavor) are only known after the consumer experiences the product. Credence attributes (nutritional content) are not visible to the consumer who must thus rely on third party certification [15]. Potemkin attributes (Fairtrade or organic practices) are process-related qualities, only visible after a close examination of the processes used in producing and handling of the product [9].

Among these, credence and Potemkin attributes are usually not visible to consumers and can be made accessible by tracing the prove ${ }_{4}$ nce of information along the supply chain [9]. Doing so requires information integration across the entire supply chain and leads to the requirement that sustainability values be integrated into supply chain.

\subsection{Information, information technology \\ and sustainable supply chain management}

Interest in incorporating sustainability into supply chain management began to grow with a shift from seeing sustainability purely from a technical stand point to considering it from a business and policy perspective. Companies became widely recognized as important actors in addressing sustainable development [17, 18], which created immense external pressure from government, the public and non-governmental organizations forcing companies to integrate sustainability into their practices $[1,14,19,20]$. Private organizations also recognized sustainability investments as potential sources of cost reduction and improved productivity [3]. In this way, sustainability practices have become part of companies' business strategies instead of a legal burden [17, 18].
Initially, companies addressed sustainability by reducing the adverse environmental impacts of their own organization [21]. However, the interconnected nature of a supply chain brought to light that internally focused strategies are inadequate for controlling the negative spillover effect resulting from poor environmental performance of supply chain partners [21]. Consequently companies started to change their environmental management practices by considering the environmental impact of the entire supply chain from production, consumption and customer service to pest-consumption of products $[1,14,18,21]$.

Managing sustainability across the whole supply chain underscores the need for supply chain partners to understand each other's capabilities to collaborate with each other [14] as well as share information about their sustainable practices. As such, information systems, information technologies and information integration constitute key drivers in enabling the integration of sustainable consumption and sustainable supply chains [22]. Sharing information becomes especially important with the increasing demand for accurate, timely and traceable information about the sustainability of companies' products and practices, particularly in food and agriculture industry [23-27].

Examples of information technology deployed to improve information flows and coordination in supply chains include EDI-based (Electronic Data Interchange) and XML-based e-Business frameworks [2, 27]. On the more technical side, researchers are pointing to the need for developing information architectures to facilitate information sharing among participants in the supply chain [2830]. Other perspectives in information systems research put emphasis on understanding how much information is shared, which capabilities are needed to develop these information systems, and consequences of the use of information technology on performance [31].

Although discussions of how modern information communication technologies can make it possible to design and develop information-driven supply chains abound in the literature, adoption levels are still low [32]. Moreover, most of this research focuses on using information systems to create short term efficiencies and costs savings [33], missing the strategic opportunity of using information systems to create and share market knowledge as a source of value [33]. Thus far, researchers in the area of industrial ecology have identified new strategic needs and objectives related to sustainability in supply chains $[34,35]$. While the need for such coordination is becoming apparent, efforts to create information-driven supply systems and infrastructure are currently in their initial stages. Consequently, although much information exists to facilitate searching for and contracting with more sustainable partners worldwide and to provide consumers with information regarding 
sustainable practices, the information is poorly integrated and largely disconnected [35]. In addition, some authors argue that supply chain stakeholders may have incentives to manipulate shared information [36]. This opens the door to questions concerning stakeholderś motivations to share information in supply chains. In fact, questions related to distribution of value and shifts in bargaining power constitute key motivations already explored in current information systems research $[37,38]$.

Finally, sustainable supply chain management technologies are not free. Creating and sustaining large scale information systems will impose additional costs on producers, retailers, and everyone else in the supply chain. Nonetheless, current information systems research has shown that information sharing promotes efficiencies and cost reductions in the supply chain [33], and it has also been suggested that information sharing may create value through marketing intelligence [33] though it is difficult to quantify the positive impacts of such investment [22]. Likewise, competition and market conditions make the distribution of such benefits along the supply chain inequitable and uncertain [37-39].

In summary, current studies call for research into integrating sustinable consumption and sustainable supply chain [4]. Such integration requires information sharing and traceability to reduce information asymmetry across the supply chain. However, current research has mostly investigated these issues independently. The growing body of scholarship tends to separate consumption from production. The most impressive attempt to investigate the integration of sustainable consumption and production was conducted by Mont and Bleischwitz [40] who examined the relationship of sustainable consumption and resource management through the lens of life-cycle analysis. They pointed at the potential synergy between sustainable consumption and resource management, and drew attention to the lack of exploration of the linkage between the two elements [40]. Similarly, a review of current scholarship on sustainability called for joint analytical examination of production and consumption [41, 42]. To achieve information integration and improve traceability for consumers, an interoperable data architecture that would enable data and information sharing across different organizations along the supply chain is needed [13, 43, 44].

\section{Methods}

The research reported here was part of a project that aimed to develop a prototype data architecture and a set of standards to share product-related information. This paper focuses on our analysis of the main challenges to integrate data along the supply chain, following a case study 2proach [45-47]. According to Yin [47], case studies are appropriate to answer "how" and "why" questions. Given that our research explores how do different challenges to data sharing affect the development of data architectures such as I-Choose, we chose this methodological approach. Our choice of coffee supply chain enabled us to keep our research focused on a product with fairly advanced product labeling and inspection standards, while maintaining a relatively tight research boundary.

This paper presents main challenges and requirements for data producers/stewards to share their data to support an interoperable data infrastructure, which would in turn support information sharing among different stakeholders in the sustainable coffee supply chain in the NAFTA region. To increase the validity of the study, we used multiple sources of information including semi-structured interviews and secondary data.

We conducted a series of 44 semi-structured interviews designed to gain an in-depth understanding of the issues, requirements and challenges for data owners/providers to source their data in support of an interoperable data framework for the certified sustainable coffee supply chain (Table 1). Each interview lasted between 45 and $80 \mathrm{~min}$. All interviews were tape recorded and transcribed. The

Table 1 Summary of data collection methods

\begin{tabular}{|c|c|c|}
\hline Methods & Timeline & Participants/respondents \\
\hline \multirow[t]{18}{*}{ Interviews } & May-June 2012 & 44 interviews \\
\hline & $\begin{array}{l}\text { Nov } 2012-\text { Nov } \\
2013\end{array}$ & 9 producers and exporters \\
\hline & & $\begin{array}{l}5 \text { mission driven roasters and } \\
\text { importers in the US }\end{array}$ \\
\hline & & $\begin{array}{l}2 \text { mission driven roasters and } \\
\text { exporters in Mexico }\end{array}$ \\
\hline & & $\begin{array}{l}9 \text { representatives of third party } \\
\text { certification: }\end{array}$ \\
\hline & & 2 with IMO fair for life \\
\hline & & 1 with Fairtrade USA \\
\hline & & 1 with Commercio Justo Mexico \\
\hline & & 1 with Control Union \\
\hline & & $\begin{array}{l}1 \text { with internal control of UTZ } \\
\text { certified }\end{array}$ \\
\hline & & 3 with certifier agents \\
\hline & & 2 NGOs in the US \\
\hline & & 2 consumers advocates \\
\hline & & $\begin{array}{l}1 \text { coffee industry association } \\
\text { (AMECAFE) }\end{array}$ \\
\hline & & 7 medium producers in Mexico \\
\hline & & 2 coffee cooperatives \\
\hline & & 3 specialty coffee shops \\
\hline & & 2 large intermediaries in Mexico \\
\hline
\end{tabular}


interview protocol was developed by an interdisciplinary team of researchers with several stages of revision and refinement. The final protocol included the following topics: the mission and objectives of the organization represented by the interviewee, an exploration of information that is currently shared by their organization as well as information that should be shared, the level of trust in the information provided, barriers and incentives to sharing data, and lastly collaboration, governance and certification processes. To increase internal validity, we shared a summary of the results and analysis with key informants, asking them for clarifications and further insights.

Data analysis included the identification of key themes in the data as well $a_{2}$ a process of comparing and contrasting the case and current theory in an iterative process [45]. Following common practices in qualitative research, data analysis started during the data collection process, allowing us to identify the gaps in the available data so that they could be addressed in subsequent data collection activities.

We also used openly available secondary data in the form of process documentation from seven major coffee certification initiatives: FLO, UTZ, 4C, RAN, C.A.F.E Practices, Organic, and Nespresso AAA. We reviewed their annual reports and/or sustainability reports (if available) for the years 2009-2011, and standards and compliance criteria documents from FLO, UTZ and 4C. The annual report and sustainability reports were important for understanding the financial capability, cost of disclosure, intensity of competition, and self-declared sustainability practices. The standards documents were needed to verify the information collected from the interviews in regards to information chains and data challenges.

\section{Findings}

This section of the paper presents our main findings drawn from the data collected through interviews, as well as analysis of the secondary data. We begin this section with a brief description of the coffee supply chain and the accompanying information flows. We identify the primary data producers in the certified sustainable coffee supply chain by identifying the most direct supply chain for certified sustainable coffee. Although certification information is collected and sometimes inspected by certifying organizations, data ownership remains with the supply chain participant being certified. We discuss issues and challenges faced by the data producers and stewards, and how these challenges affect each of the identified data producers and their ability to disclose their data. In the following section, we discuss a set of recommendations to deal with these challenges.
4.1 Main actors and information flows in the coffee supply chain

Through our interviews and document analysis we identified two types of coffee producers, small and medium farmers. There are no large farmers in Mexico because of land regulations put into effect after the Mexican revolution in the early twentieth century. As shown in Fig. 1 below, medium-sized farms tend to integrate the value chain from production to roasting, and most of them have their own brands that are sold in the national and international markets. Some medium farmers interested in exporting have coffee certifications such as UTZ or the Rainforest Alliance.

Small farmers typically form a cooperative to expand their reach for marketing their coffee. Because these cooperatives sell coffee to the roasters through brokers and intermediaries, they are most often regarded as producer cooperatives.' In some cases, small local cooperatives organize themselves in cooperative confederations, involving in some cases thousands of members. In Mexico, main organizations such as TosepanTitataniske, UCIRI or CEPCO are examples of these confederations. In these cases, local cooperatives often function as local intermediaries between the small farmers who are their members, and larger organizations to which the local cooperative belongs. It is common that the large cooperative or confederation of cooperatives represents members in the certification process. Any data sharing has to be decided by cooperative members in their regular meetings.

Larger intermediaries in the supply chain, such as specialty roasters, buy products from different local intermediaries and sell to different types of clients. In the case of specialty roasters the local intermediary is usually a wellknown certified coffee taster who builds relationships with producers to improve their production methods, and provide the specialty roaster with high quality coffee to be sold directly to the end consumer in small coffee shops. Finally, other large intermediaries gather coffee to be sold to either national or international rosters. The large intermediaries that we were able to interview were certified by $4 \mathrm{C}$, and belonged to the Nestlé supply chain. These intermediaries are usually in charge of the dry process, which prepares the coffee beans for roasting. In terms of certification, it is again this large intermediary who represents all producers that sell coffee beans to him or her in the certification process. Decisions on sharing data resulting from these processes are complex given that there is no specific governance system among producers and intermediaries. However, Nestlé requires intermediaries to share information about producers and inspection processes, and

\footnotetext{
$\overline{1}$ See Raynolds et al. [48].
} 


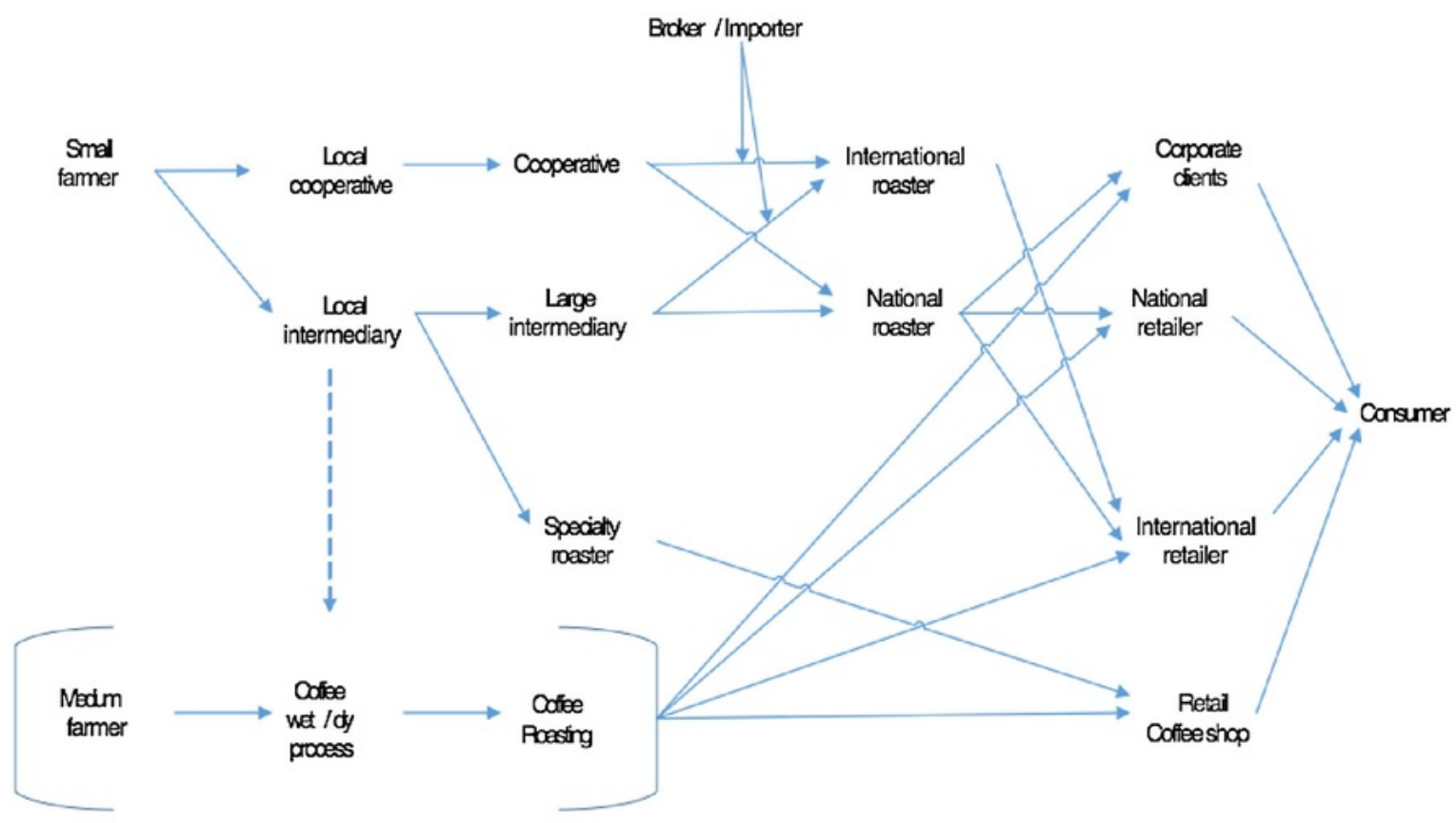

Fig. 1 Product and product information flow in certified sustainable coffee supply chain

compliance is either a requisite to be a Nestlé provider or it has an important influence on the prices.

Figure 1 depicts the main actors in the sustainable coffee production and the flow of product and product information among them as described above. This figure does not include third party certifiers, whose role will be described later.

According to the theory of value chain governance [49], the supply chain environment is very complex based on three factors: complexity of information required to sustain transactions, capability to codify knowledge and information, and stakeholders' capacity to comply with the requirements. The certified sustainable coffee supply chain is no exception, involving multiple stakeholders with their own information systems holding different elements of information. To simplify the complexity of this chain, we identified the most direct trading route for certified sustainable coffee and the accompanying information flows. The interview findings and secondary data analysis indicate that the shortest path of trade consists of producers, exporters, importers, roasters, and third party certifiers (Fig. 2 below). Among these five actors, two are essential data producers of certification and inspection data (producers, roasters), one is data producer/steward (third party certifiers), and two are mediators (exporters and importers).Data ownership is distributed and in some cases it is complicated to assign ownership to a specific data set.

In general, two major types of information flow along the chain: trading information and certification information.

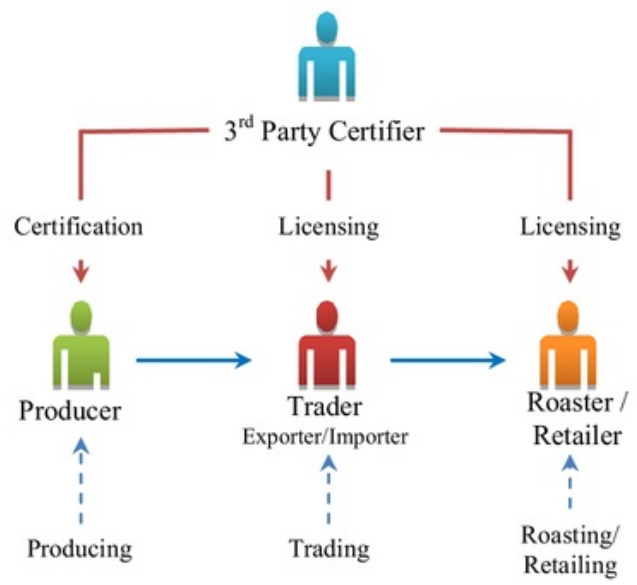

Fig. 2 Shortest path in sustainable certified coffee supply (adopted from Sayogo [50])

Trading information refers to information that accompanies the trading of sustainable products and is captured in the trading documents such as invoices, bills of lading, farmer contracts and financial contracts. Certification information refers to information that is collected by a certification body during the process of granting sustainable certificates to companies in the supply chain. These two types of information are private, interrelated, and 
already shared to some extent in private exchanges among supply chain participants. As we mentioned before, there is no single data owner.

The envisioned functionality of I-Choose is to facilitate the extraction of both trading and certification information in sustainable supply chains through enabling integration and standardization of certification and inspection data. The data architecture provides a method to integrate certification information from various data sources while at the same time enabling standardization of an agreed set of terms and semantics for currently fragmented certification and inspection schemes. By amassing standardized data from both trading and certification domains, the power users, such as consumer advocates, could verify the integrity of data as well as utilize more comprehensive data to help end-consumers make purchase decisions. This comparability function in itself enhances the accuracy of data being collected. For instance, by checking roaster's certification results for consistency against their trading information the system enables greater degree of information verification.

As explained earlier in this section, the information that flows along the supply chain for certified coffee is diverse, originating from different sources and being produced in different formats. Making such information widely accessible in a shareable format is thus a complex task for the developer as well as data owners/producers. In the next section we present issues and challenges associated with sourcing public data from data producers/stewards and how these issues and challenges affect them. ${ }^{2}$

\subsection{Challenges for sourcing data: the perspectives of data producers/stewards}

The ability of platforms supported by data architectures such as I-Choose to provide trusted and accurate recommendations is highly dependent on the accessibility of data from data producers and data stewards. The interview findings point to several challenges facing data producers/ stewards in sourcing their data. This section outlines these challenges from the perspective of producers, roasters and third party certifiers. Table 2 summarizes the challenges.

\subsubsection{Challenges of data collection, accuracy, and credibility \\ 3}

The first step toward making information more widely available is ensuring that the needed data is collected and is accurate and credible. Our interview findings indicate that producers, roasters and third party certifiers face a number

${ }^{2}$ A more detailed description of challenges for the stakeholders of sustainably certified coffee supply chain is [50, 51].
Table 2 Summary of issues and challenges for primary data producers

\begin{tabular}{|c|c|c|c|}
\hline \multirow[t]{2}{*}{ Challenges } & \multicolumn{3}{|c|}{ Primary data producers/stewards } \\
\hline & Producers & Roasters & $\begin{array}{l}\text { 3rd party } \\
\text { certifiers }\end{array}$ \\
\hline $\begin{array}{l}\text { Ensuring data quality, integrity } \\
\text { and security }\end{array}$ & $\sqrt{ }$ & $\sqrt{ }$ & $\sqrt{ }$ \\
\hline $\begin{array}{l}\text { Ensuring consistent } \\
\text { documentation }\end{array}$ & $\sqrt{ }$ & & \\
\hline Limited technical expertise & $\sqrt{ }$ & $\sqrt{ }$ & $\sqrt{ }$ \\
\hline $\begin{array}{l}\text { Limited access to } \\
\text { communication technology }\end{array}$ & $\sqrt{ }$ & - & - \\
\hline $\begin{array}{l}\text { Data ownership and conflict of } \\
\text { disclosure policy }\end{array}$ & - & - & $\sqrt{ }$ \\
\hline $\begin{array}{l}\text { Confidentiality, commercial } \\
\text { privacy and economic value of } \\
\text { information }\end{array}$ & $\sqrt{ }$ & $\sqrt{ }$ & $\sqrt{ }$ \\
\hline Cost of disclosing information & $\sqrt{ }$ & $\sqrt{ }$ & \\
\hline
\end{tabular}

of challenges when attempting to collect accurate and credible data.

Producers The producer in sustainable certified coffee is usually a cooperative of small farmers or a medium sized plantation owner. Certification and inspection data for certified sustainable coffee consists of many pieces of data collected directly from small farmers by their cooperative or by local intermediaries (Fig. 1). Farmers are the smallest unit of data source and ensuring continuous data supply from them is crucial for the whole supply chain of certified coffee. The interviews indicate that asking farmers to maintain consistent documentation of data is the most difficult challenge for two reasons. First, farmers see no value in maintaining documentation other than obtaining a price premium. Without a premium farmers saw documentation as a waste of their time. Second, farmers are reluctant to record information about their products if the documentation process is complicated. As a consequence, producers frequently have to assume additional costs to ensure data is collected. Producers often distribute predefined and easy-to-complete forms to farmers or assign staff, usually from their internal control unit, to solicit data from farmers through interviews. Larger confederations of cooperatives usually hire some cooperative members to manage the process of data gathering, as well as the associated information systems. In some cases, such as the $4 \mathrm{C}$ program, large intermediaries gather data from producers and other local intermediaries.

Additionally, producers have to contend with ensuring accuracy and credibility of data in situations where small farmers, motivated by geographical location and financial issues, sell their coffee to local intermediaries who in turn sell it to producers. Our interviewees stated that these local 
intermediaries, especially those who are not part of a cooperative, occasionally fabricate information about the certification of the product in order to quickly fulfill orders. Most often, these intermediaries record and report noncertified products as certified. This is because for some certifications local intermediaries are not part of the premium distribution list. This issue is significantly lessened when the producer is a local cooperative whose information can generally be more trusted due to well established internal controls.

Roasters Roasters' primary challenge is ensuring access and credibility of data. Roasters generally procure their coffee from traders or importers. Our interviews indicate that some importers do not want to reveal their information or source of information for two reasons. First, some traders "cheapen the spirit of fair trading" by manipulating the producers in the negotiation. These traders thus do not wish to disclose their sources of information. Second, hoarding or hiding information is seen by some traders as a competitive advantage and strategy to mitigate threat of substitution. As a result, roasters are often faced with incomplete and inaccurate data regarding the origin of the product they purchase, which in turn affects their ability to provide accurate and complete data for their roasted product.

Third party certifiers Data collection challenges experienced by third party certifiers coincide with challenges faced at producers' level. Only few cooperatives have computerized information systems, and the most common form of tracing are small pieces of paper attached to the bags of coffee. Our interviewee from Control Union, a globally recognized certification agency, indicated that inspector or auditor who conduct audits in the field are often faced with incomplete or unavailable information for their audit. Since audit is conducted once a year, the information gaps hinder the ability of inspectors to understand what happens between audits. In addition, human judgment is involved during the audit process. Despite the existence of criteria governed by standards, inspectors and evaluators must exercise judgment in applying the criteria in the field. Take the compliance criteria of Fairtrade (FLO) as an example. Each criterion is measured based on five levels of measurement and achieving at least the third level is required for compliance. The measuring indicators in each level are not always prescriptive. For example, the third level indicators for criteria 3.2.22 of FLO-training members on appropriate use of fertilizers-are: (a) at least $50 \%$ members have been trained, and (b) content of training was sufficient. The inspectors need to use their judgment based on their expertise and experience to measure the sufficiency of the training content. Due to these limitations, audit reports, which are at the core of certification and inspection data, are prone to human judgment biases. Without adequate information, auditors must use their experience in deciding the conformity of the applicant to the required criteria and standards.

\subsubsection{Challenges of publishing data: limited technological capability}

For producers, roasters and third-party certification bodies, opening data is also challenging due to three aspects of limited technological capability: limited technical expertise, limited access to technology (hardware), and issues with communication technology.

Producers Limited access to technology affects communication between producers and traders. For producers, limited access to communication technology lengthens the communication paths with traders. Very often these producers have to assign additional staff in a location with access to technology to help with communication. Technology capabilities could also help during the data collection process at the small farmer level. However, technical expertise and access to technology is a major challenge at that level in the supply chain. Our interviews of producers point to the challenge of accessing technology due to the geographical remoteness of their location. For instance, when trying to sell organic coffee such as US Department of Agriculture (USDA) organic, they find it challenging to use the certifier's information system to publish the required organic certificate. Additionally, technical expertise that is needed to interpret the standards and proceduresis a scarce resource among cooperative members.

Roasters and third party certifiers Interviewees from roasters and third-party certifiers asserted that they are sometimes limited by their lack of technical expertise despite their willingness to disclose their data. For instance, roasters and importers among our interviewees abandoned their efforts to publish coffee contract documents online due to their limited technical expertise. Our interviewee from Fair for Life certification indicated that it limits the publication of certification ratings and indicators on its website due to technological constraints. The interviewee indicated that they have to use an external programmer at additional cost. Although some certifying organization may have the proper set of databases, and have attempted to publish certification data, the lack of technology in the field and the lack of standard processes to update the information creates an additional challenge.

\subsubsection{Challenges of data ownership and conflict of disclosure policy: perspectives of third party certifiers}

The majority of data related to certification and inspection as well as to sustainable trading is in the stewardship of the 
third-party certification body that collects and stores this data. Opening the data available in the third party certification database would provide substantial benefits for the development of innovations to support sustainable consumption such as I-Choose platform. However, third party certifiers face two interrelated challenges to publishing such data: data ownership and conflict with applicant's disclosure policy.

Data ownership Certification and inspection data is owned by the applicant, usually the producer or roaster, and not the third party certifier. Releasing, accessing, or publishing this data requires consent from the applicant as the owner. Interviewees from Fair for Life certification indicated that the requirement for data owners to publish certification results is voluntary, and there is an option for the applicants to opt out from this requirement. Consequently, certifiers are limited in the amount of data they can publish despite their inclination to publish all information online. In most cases, only certification status can be made public to avoid fraud, but even that is challenging as maintaining the information up-to-date imposes additional costs on stakeholders in the certification process.

Conflict of disclosure policy The disclosure policy of the certification body often conflicts with the disclosure policy of the applicants with regard to publishing certification data. Applicants have their own information policy governing the release of their data. Applicant takes into consideration their own disclosure policy before deciding to publish their certification data; and they are especially concerned about the impact to their brand and reputation.

\subsubsection{Challenges to confidentiality, commercial privacy and economic value of information}

The interviews identified challenges related to the lack of information policies that would address the types and amount of data to be disclosed, and restrictions to disclosure especially in terms of privacy and confidentiality of information. The interviewees, especially those from mission-driven roasters, importers and third party certifiers, point out that a major barrier to opening their data is making a decision about what kind of information and how much information to disclose in order to add value without violating disclosure restrictions. The interviewees showed willingness to open their data if doing so adds value to the organization and restrictions related to confidentiality and economic value of information can be implemented easily. They were also in agreement about disclosing information that educates consumers on topics related to coffee quality and general processes. Nevertheless, some information is closely related to gaining competitive advantage and disclosing it potentially endangers the organization's market share. There is also the issue of ensuring commercial privacy. As alluded to in the paragraph above, disclosing certification results might compromise the reputation and competitive advantage of the applicants.

\subsubsection{Cost of disclosing data/information}

Disclosing data and information to support sustain 3 le consumption can be costly for the data producers. The interviewees from mission-driven roasters, importers and third party certifiers indicated that indirect costs of certification can be high even if mechanisms exist to mitigate direct costs. For instance, third-party certification generally obliges producers to maintain records and documentation to support the certification and/or traceability efforts. Maintaining records and documentation is a major cost for coffee producers. The revenue model of coffee producers does not depend on their ability to disclose information. As discussed in sections above, the coffee producers are only incentivized to maintain documentation by a price premium.

Likewise, publishing their data online is also costly for both roasters and third-party certification bodies. For roasters, additional work is required to transform nondigital information into publishable digital format, which increases expenses. Although the interviewees from small mission-driven coffee roasters asserted that transparency, in the form of storytelling, is one of their main strategies for attracting consumers, it is difficult to find a direct connection between the transparency strategy and revenue. For third-party certification bodies, the information can be extensive; for example, audit results might be 30 pages long, with 10 or 20 control points for each category, which makes publishing such data very costly. Similarly, as discussed in Sect. 4.3.4 disclosing information relates closely to the reputation of the third party certifiers since one of their responsibilities is ensuring commercial privacy of data owners.

\section{Developing interoperable data architecture in sustainable supply chains: from challenges to requirements}

In summary, through our interviews we have identified seven challenges as presented in Table 2. Based on the connections between the identified challenges and the different types of data producers, we can make three observations. First, some challenges affect all primary data producers, such as ensuring data quality and integrity, confronting limited technical expertise, and safeguarding confidentiality and privacy of certain information.

Second, some challenges are uniquely related to particular data producers/stewards. These challenges plausibly 
correlate with their business profile. For instance, data ownership and conflict of disclosure policy is a challenge uniquely related to third party certifiers. In their role as the stewards of data entrusted to them, third party certifiers have limited ability to publish data in their care.

Third, some challenges require technological solutions, while others require combination of technology and governance solutions. For instance, the challenge of limited technical expertise and limited technology access pertaining to the issue of semantic incompatibilities among different standards needs a technological solution such as the use of semantic-based technologies. On the other hand, the challenge of ensuring data quality and integrity, consistent documentation, balancing commercial privacy, confidentiality and disclosure, and mitigating costs of disclosing information requires that technological solutions be supported with robust information policy and governance mechanisms.

As such we argue that the challenges identified from the interviews entail several requirements that developers of data architecture for interoperable sustainable supply chain such as I-Choose need to take into consideration. In the following paragraphs, we discuss these requirements in more detail, highlighting four of them as key to building such architecture.

\subsection{Ensuring data quality, integrity and security}

I-Choose envisions that a variety of organizations could publish and extract certification and inspection data, seeking comparative information to evaluate specific products across a variety of data sources in the supply chain. As a complex socio-technical system, I-Choose requires integration of data and information that is under the ownership and stewardship of public and private entities. While information quality and integrity has always been an issue of concern even in situations with a single information source, it will be even a bigger challenge in the case of a platform that is designed to integrate information from multiple disparate information sources. Thus, creating technical and process mechanisms to ensure information integrity and security is essential for the data to be trustworthy. Information security for platforms that are built upon data architecture such as I-Choose is particularly important because data that is relevant might often be considered confidential, proprietary and private. Thus, learning from Rindfleisch's [52] arguments, a platform that is built upon I-Choose architecture needs to have or create robust access controls to authenticate the diverse users, and a protocol to maintain data quality and integrity. We thus argue that the developers must find effective ways to involve primary stakeholders in designing information security mechanisms from the beginning. Information security mechanisms that will be developed with the help of primary stakeholders will take into consideration the issues connected to access control and data quality. This is particularly important because, as argued by Mishra et al. [36], supply chain stakeholders may have incentives to manipulate shared information. Likewise, as we found from the interviews, some stakeholders in sustainable supply chain may have incentives to fabricate information.

Ensuring information security serves three objectives. First and foremost, it will enhance trust in the published data and its re-use. Second, confidence in data protection could motivate more data producers to participate. Finally, information security mechanisms that consider the needs of all stakeholders-big and small-diminish the negative impacts on competitiveness for technologically and financially disadvantaged participants.

\subsection{Designing information policy balancing commercial interests and openness}

Our interviews point to economic motivations for opening information, but only under certain conditions. The interviewees indicated a willingness to open their information only if doing so adds value to their organizations, and if adequate restrictions can be easily implemented to safeguard confidential information and information of competitive value.

Thus, designing information policy that balances the need for supply chain transparency and ability of businesses to remain competitive is key. Our interviewees indicated that private entities, in particular mission-driven companies, are willing to disclose information if disclosure adds value to their relationships with existing and potential consumers, and if privacy and proprietary information is not compromised. As argued by extant studies, competition and market conditions significantly affect the benefit of sharing information in a supply chain [37-39]. Hence, the issue is to ensure that policies for data disclosure do not endanger the competitive advantage of the companies, and that the policies also address safeguarding proprietary information such as trade secrets. A lesson from studies in economics can be used as a starting lens. These studies argue that the timing and manner of disclosure supersede the decision of whether companies need to disclose. Appropriate timing and method of information disclosure mitigates the company's fear that disclosure will disrupt their market position and thus generate appropriate returns from disclosing information [53].

\subsection{Designing appropriate governance structures}

Establishing a governance structure is crucial for all large system development projects, but perhaps especially so for the development of platforms dealing with the inherent 
complexity of supply chains such as I-Choose. As our interview data shows, developing interoperable data architecture within sustainable supply chains requires a great deal of trust building and negotiation among a group of actors with disparate interests, suggesting that a collaborative or participatory governance model might be the most appropriate choice.

Collaborative or participatory governance models are characterized by greater (although not complete) decision making equality between smaller and larger supply chain actors, and by the centrality of pro-sustainability actors within the supply chain network [54]. Collaborative governance goes beyond merely consulting stakeholder groups over policies and rulemaking, allocating a greater degree of discretion to each partner organization [55].

Collaborative models can have several advantages over other more captive, ad hoc, or hierarchical approaches that potential I-Choose stakeholders may want to consider. Collaborative models involve joint rule development through a process that takes into account the diverse capabilities of supply chain actors to comply with sustainability standards. This development process can be important for actors who want to avoid weak links in their sustainability-focused value chain [54]. Embarrassing revelations about a firm's suppliers can have a disastrous effect on that company's reputation, undoing expensive corporate social responsibility actions in an instant.

Collaborative models also require longer-term relationship building in order to develop and improve those rules through an iterative process. It is argued that longer-term relationships produce more stable and less ad hoc supply chains, thus making it easier to trace the origins of a product and verify its sustainability and providing more stable incomes for sustainable producers.

Research shows that collaborative or participatory governance models produce the best results when stakeholders face a common problem with no agreed upon solution [56, 57]. These circumstances both provide stakeholders with the incentives to negotiate and form trusted relationships with one another and the freedom to develop commonly agreed upon solutions. Three problems were identified that are common to our three groups of data producers/stewards: ensuring data quality, integrity, and security, confronting limited technical expertise, and safeguarding the confidentiality and privacy of certain information with commercial value. It is likely that these shared problems may be most effectively dealt with as part of an ongoing collaboration.

Collaborative governance models also work best when failing to create them would produce real, negative consequences for multiple participants [58, 59]. Thus, becoming an I-Choose stakeholder might be attractive to firms that wish to verify the sustainability of each step of their value chains [see 49,60,61], and to producers and retailers who want to more effectively differentiate their products within the marketplace [51]. Our interviews indicated that potential I-Choose stakeholders do have a shared goal: they were willing to disclose more of their data if it would lead to them obtaining a price premium from their sustainable products.

In order to address the challenges we have identified, I-Choose stakeholders could create a participatory governance model to work towards this shared goal. The ultimate objective for the collaboration would be to ensure the progressively wider release of product data in ways that can inform consumers and encourage developers and other groups to use the information in innovative ways, furthering the goal of obtaining a price premium by providing highly trusted information.

The key to this process would be establishing a basis for 'principled engagement', in other words a common understanding of the ways in which different stakeholders use central concepts and terms [62]. Experts from the workshop that we $\mathrm{w}_{4}$ onducted in 2011 point to this issue as a crucial element for developing data architecture such as I-Choose. Their concern lies in the diversity of certification standards and protocols applied to the sustainable certified coffee supply chain $[48,63]$, each using different criteria and processes for assessment and certification. The ecolabelindex, an information aggregator on eco-certifications, is currently tracking 460 ecolabels in 197 countries, and 25 industry sectors (http://www.ecolabelindex.com/). Consequently, data architecture such as I-Choose needs to take into account these diversities by creating semantic compatibilities among standards and protocols.

Technically, the development of semantic compatibilities and common language and schema among diverse knowledge ${ }_{4}$ s possible through ontology. The ontology will enable the creation of a "shared and common understanding of a domain that can be communicated between people and application systems [64] ", and serve as a language to support data translation and queries from different system designs [65]. The second step would be to establish an iterative method for rule creation, where rules are established, reviewed and updated by a representative body that balances decision making authority between larger and smaller groups [66]. This iterative process would attempt to create a 'virtuous cycle' of collaboration by focusing on small achievements at first, shown to be a successful strategy within existing governance experiments [67].

\section{Concluding remarks}

Information asymmetry in the relationship between endconsumers and other actors in the supply chain is argued to be one of the main barriers to the expansion of sustainable 
consumption [4]. The key to addressing these problems lies in making vast amounts of disparate data and information regarding sustainability practices accessible across the supply chain and usable by end-consumers.

A central missing element is a platform that combines interoperable data standards and architecture with policy and governance mechanisms. We posit that building such platform obliges the developer to recognize four major issues to be considered in developing data standards to support interoperable platform for sustainability as perceived by key stakeholders in the certified sustainable coffee industry. First, the developer needs to ensure quality, integrity and security of data being used and or exchanged using the platform. Second, they need to acknowledge that some data owners have limited technical expertise and factor this into the platform development. Third, the developer must understand the complexity and diversity of stakeholders in the supply chain as well as the possible incompatibilities of the concepts and processes used by them. Finally, they must be sensible to the possible misuse of the platform by irresponsible or dominant users to undermine powerless firms and agents, and confront the issue in developing the platform. The results from the empirical analysis also demonstrate that developing interoperable architecture as a foundation to develop a platform that integrates the whole supply chain requires more than technical considerations. We found that some technical elements need to be complemented with governance mechanisms to ensure fair and proper use of the system.

We conclude the paper by calling attention to a number of areas for future research. In terms of technical research, information security and trust emerge as major area of research for platforms such as I-Choose. For example, a better model of trust building is needed that would recognize context-sensitive information and complexity and heterogeneity of agents in a sustainable supply chain. In the scenario envisioned by I-Choose, data extraction efforts by heterogeneous actors might become common, resulting in increasing risk of security breaches. A trustworthy architecture would have to recognize and respond to this risk.

One possible model of trust management that recognizes the complexity and heterogeneity of agents in a semantic web-based platform is flexible trust management. A flexible trust management model would be useful for negotiation of different policies and protocols for access to information from platforms such as I-Choose. Such a model could be used to assess and balance between the acceptable trust level and risk levels for each particular agent in the sustainable supply chain. The ensuing research should lead to a new model of trust that finds the right balance between trust indicators that have enough details to induce acceptable level of trust, but are scalable for the stakeholders in the entire supply chain, big or small.
The economic value and proprietarynature of supply chain information render the implementation of platforms such as I-Choose infeasible without a complementing governance system. The challenges and issues outlined in the previous section call for studies to understand the appropriate governance model. It is important to explore the strengths and weaknesses of the various governing mechanisms and provide answers to questions such as how can a balanced approach be established, and what are the contingent factors? In addition, the economic repercussions of disclosing information necessitate governance intervention to draft information policies governing the three exceptions to disclosure: privacy, security and confidentiality. Research that would provide a better understanding of the confidentiality and commercial privacy issues in the context of a platform such as I-Choose is still very much needed. Future studies should address questions such as what data is confidential, and what would be the impact of a breach of such data on the organization.

\section{References}

1. Linton JD, Klassen R, Jayaraman V (2007) Sustainable supply chains: an introduction. J Oper Manag 25:1075-1082

2. Fuchs DA, Lorek S (2005) Sustainable consumption governance: a history of promises and failures. J Consum Policy 28:261-288

3. Mont O, Plepys A (2008) Sustainable consumption progress: Should we be proud or alarmed? J Clean Prod 16:531-537

4. Seyfang G (2005) Shopping for sustainability: Can sustainable consumption promote ecological citizenship? Environ Polit 14:290-306

5. Eisenhardt KM (1989) Agency theory: an assessment and review. Acad Manag Rev 14:57-74

6. Fama EF, Jensen MC (1983) Separation of ownership and control. J Law Econ 26:301-325

7. Akerlof GA (1970) The market for "lemons": quality uncertainty and the market mechanism. Q J Econ 84:488-500

8. Mishra DP, Heide JB, Cort SG (1998) Information asymmetry and levels of agency relationships. J Mark Res 35:277-295

9. Jahn G, Schramm M, Spiller A (2005) The reliability of certification: quality labels as a consumer policy tool. J Consum Policy 28:53-73

10. Luna-Reyes L, Zhang J, Whitmore A et al (2014) Full information product pricing: an information strategy for harnessing consumer choice to create a more sustainable world. Commun Assoc Inf Syst 34:1

11. Graham M, Haarstad H (2011) Transparency and development: ethical consumption through Web 2.0 and the internet of things. Inf Technol Int Dev 7:1-18

12. Watts S, Wyner G (2011) Designing and theorizing the adoption of mobile technology-mediated ethical consumption tools. Inf Technol People 24:257-280

13. Jarman H, Luna-Reyes LF, Zhang J, Whitmore A, Picazo-Vela S, Andersen DL, Tayi GK, Pardo TA, Andersen DF, Sayogo DS (2011) I-Choose: consumer choice, digital government, and sustainability in North America. Presented at the APPAM Research Conference, Washington, DC

14. Vachon S, Klassen R (2007) Supply chain management and environmental technologies: the role of integration. Int J Prod Res $45: 401-423$ 
15. Darby MR, Karni E (1973) Free competition and the optimal amount of fraud. J Law Econ 16:67-88

16. Nelson P (1970) Information and consumer behavior. J Polit Econ 78:311-329

17. Angell LC, Klassen RD (1999) Integrating environmental issues into the mainstream: an agenda for research in operations management. J Oper Manag 17:575-598

18. Matos S, Hall J (2007) Integrating sustainable development in the supply chain: the case of life cycle assessment in oil and gas and agricultural biotechnology. J Oper Manag 25:1083-1102

19. Sarkis J, Zhu Q, Lai K (2011) An organizational theoretic review of green supply chain management literature. Int J Prod Econ 130:1-15

20. Zhu Q, Sarkis J (2004) Relationships between operational practices and performance among early adopters of green supply chain management practices in Chinese manufacturing enterprises. J Oper Manag 22:265-289

21. Hsu C-C, Tan KC, Zailani SHM, Jayaraman V (2013) Supply chain drivers that foster the development of green initiatives in an emerging economy. Int J Oper Prod Manag 33:656-688

22. Wolf J (2011) Sustainable supply chain management integration: a qualitative analysis of the German manufacturing industry. J Bus Ethics 102:1-15

23. Collins CM, Steg L, Koning MAS (2007) Customers'values, beliefs on sustainable corporate performance, and buying behavior. Psychol Mark 24:555-577

24. Locke R, Romis M (2007) Improving work conditions in a global supply chain. MIT Sloan Manag Rev 48:54-61

25. Locke R, Kochan T, Romis M, Qin F (2007) Beyond corporate codes of conduct: work organization and labour standards at Nike's suppliers. Int Labour Rev 146:21-40

26. Opara LU (2003) Traceability in agriculture and food supply chain: a review of basic concepts, technological implications, and future prospects. J Food Agric Environ 1:101-106

27. Wilson TP, Clarke WR (1998) Food safety and traceability in the agricultural supply chain: using the Internet to deliver traceability. Supply Chain Manag Int J 3:127-133

28. Bardhan IR, Demirkan H, Kannan PK, Kauffman RJ, Sougstad R (2010) An interdisciplinary perspective on IT services management and service science. J Manag Inf Syst 26:13-64

29. Lyons AC, Coronado Mondragon AE, Bremang A, Kehoe DF, Coleman J (2005) Prototyping an information system's requirements architecture for customer-driven, supply-chain operations. Int J Prod Res 43:4289-4319

30. Xu LD (2011) Information architecture for supply chain quality management. Int J Prod Res 49:183-198

31. Klein R, Rai A (2009) Interfirm strategic information flows in logistics supply chain relationships. MIS Q 33:735-762

32. Steinfield C, Markus ML, Wigand RT (2011) Through a glass clearly: standards, architecture, and process transparency in global supply chains. J Manag Inf Syst 28:75-108

33. Malhotra A, Gosain S, Sawy OAE (2005) Absorptive capacity configurations in supply chains: gearing for partner-enabled market knowledge creation. Mis Q 29:145-187

34. Bayat A, Sundararajan S, Gustafson HR Jr, Zimmers EW Jr (2011) Sustainably driven supply chains. Ind Eng 43:26-31

35. Davis C, Nikolic I, Dijkema GP (2010) Industrial Ecology 2.0. J Ind Ecol 14:707-726

36. Mishra BK, Raghunathan S, Yue X (2007) Information sharing in supply chains: incentives for information distortion. IIE Trans 39:863-877

37. Clemons EK, Row MC (1993) Limits to interfirm coordination through information technology: results of a field study in consumer packaged goods distribution. J Manag Inf Syst 10:73-95

38. Johnston HR, Vitale MR (1988) Creating competitive advantage with interorganizational information systems. MIS Q 12:153-165
39. Han K, Chang YB, Hahn J (2011) Information technology spillover and productivity: the role of information technology intensity and competition. J Manag Inf Syst 28:115-146

40. Mont O, Bleischwitz R (2007) Sustainable consumption and resource management in the light of life cycle thinking. Eur Environ 17:59-76

41. Lebel L, Lorek S (2008) Enabling sustainable production-consumption systems. Annu Rev Environ Resour 33:241-275

42. Srivastava SK (2007) Green supply-chain management: a stateof-the-art literature review. Int J Manag Rev 9(1):53-80

43. Pardo TA, Burke GB (2008) Improving government interoperability: a capability framework for government managers. Center for Technology in Government

44. Pardo TA, Gil-Garcia JR, Burke GB (2008) Sustainable crossboundary information sharing. In: Chen $\mathrm{H}$, Brandt L, Gregg V, Traunmuller R, Dawes SS, Hovy E, Macintosh A, Larson CA (eds) Digital government: advanced research and case studies, and implementation. Springer, New York, pp 421-438

45. Eisenhardt KM (1989) Building theories from case study research. Acad Manag Rev 14(4):532-550

46. Stake RE (2006) Multiple case study analysis. The Guilford Press, New York

47. Yin RK (2003) Case study research: design and methods, vol 5, 3rd edn. Sage, Thousand Oaks

48. Raynolds L, Murray D, Heller A (2007) Regulating sustainability in the coffee sector: a comparative analysis of third-party environmental and social certification initiatives. Agric Hum Values 24:147-163

49. Gereffi G, Humphrey J, Sturgeon T (2005) The governance of global value chains. Rev Int Polit Econ 12:78-104

50. Sayogo DS (2013) Modeling incentives to disclose: smart disclosure policy, private sector transparency and demanded disclosure (Dissertation). University at Albany State University of New York, Albany, NY

51. Sayogo DS, Jarman H, Whitmore A, Tayi GK, Zhang J, Hrdinova J, Pardo TA, Andersen DF, Luna-Reyes LF, Tan X, Andersen DL (2012) A stakeholder analysis of interoperable data architecture: the case of I-Choose. In: Proceedings of the 13th annual international conference on digital government research, Dg.o'12. Presented at the dg.o, ACM, Albany, NY, USA, pp 145-154

52. Rindfleisch TC (1997) Privacy, information technology, and health care. ACM Commun 40(8):92-100

53. Stiglitz JE (2000) The contributions of the economics of information to twentieth century economics. Q J Econ 115:1441-1478

54. Vurro C, Russo A, Perrini F (2009) Shaping sustainable value chains: network determinants of supply chain governance models. J Bus Ethics 90(4):607-621

55. Donahue JD, Zeckhauser RJ (2011) Collaborative governance: private roles for public goals in turbulent times. Princeton University Press, Princeton

56. Sabel CF, Zeitlin J (2008) Learning from difference: the new architecture of experimentalist governance in the EU. Eur Law $\mathbf{J}$ 14(3):271-327

57. Sabel CF, Zeitlin J (eds) (2010) Experimentalist governance in the European Union: towards a new architecture. Oxford University Press, Oxford

58. Abbott K, Snidal D (2009) The governance triangle: regulatory standards institutions and the shadow of the state. In: Mattli W, Woods N (eds) The politics of global regulation. Princeton University Press, Princeton, NJ, pp 44-88

59. Héritier A, Lehmkuhl D (2008) The shadow of hierarchy and new modes of governance. J Public Policy 28(01):1-17

60. Jiang B (2009) Implementing supplier codes of conduct in global supply chains: process explanations from theoretic and empirical perspectives. J Bus Ethics 85(1):77-92 
61. Lim SJ, Phillips J (2008) Embedding CSR values: the global footwear industry's evolving governance structure. J Bus Ethics 81(1):143-156

62. Emerson K, Nabatchi T, Balogh S (2012) An integrative framework for collaborative governance. J Public Adm Res Theor 22(1): $1-29$

63. Horne RE (2009) Limits to labels: the role of eco-labels in the assessment of product sustainability and routes to sustainable consumption. Int $\mathbf{J}$ Consum Stud 33:175-182

64. Davies J, Fensel D, Van Harmelen F (2003) Towards the semantic web. Wiley, London
65. Lumsden J, Hall H, Cruickshank P (2011) Ontology definition and construction, and epistemological adequacy for systems interoperability: a practitioner analysis. J Inf Sci 37:246

66. Luna-Reyes, LF, Andersen DF, Andersen DL, Derrick D, Jarman $\mathrm{H}$ (2012) Full information product pricing (FIPP) regimes: policy implications for US-Mexico sustainable commerce. 3rd annual Puentes consortium symposium on the Mexico-US Border, Rice University, Houston

67. Ansell C, Gash A (2007) Collaborative governance in theory and practice. J Public Adm Res Theory 18(4):543-571 
Copyright of Information Technology \& Management is the property of Springer Science \& Business Media B.V. and its content may not be copied or emailed to multiple sites or posted to a listserv without the copyright holder's express written permission. However, users may print, download, or email articles for individual use. 
Challenges and requirements for developing data architecture supporting integration of sustainable supply chains

\section{ORIGINALITY REPORT}

5

SIMILARITY INDEX
$2 \%$

INTERNET SOURCES
$4 \%$

PUBLICATIONS
$1 \%$

STUDENT PAPERS

\section{PRIMARY SOURCES}

1 bibliotecadigital.fgv.br

Internet Source

2 Isis Gutiérrez-Martínez, François Duhamel,

Luis F. Luna-Reyes, Sergio Picazo-Vela, María

Isabel Huerta-Carvajal. "The role of joint

actions in the performance of IT clusters in

Mexico", Competitiveness Review, 2015

Publication

3 Submitted to Grand Canyon University

Student Paper

4 ctg.albany.edu Internet Source

Djoko S. Sayogo, Weijia Ran, Giri Kumar Tayi, Joanne S. Luciano et al. "Ontological Modeling

of Certification and Inspection Process to

Support Smart Disclosure of Product

Information", International Journal of Public

Administration in the Digital Age, 2016 
